\title{
O DIÁLOGO EM PAULO FREIRE: CONTRIBUIÇÕES PARA O ENSINO DE MATEMÁTICA EM CLASSES DE RECUPERAÇÃO INTENSIVA
}

Ana Cristina da Silva Ambrosio

Programa de Pós Graduação em Educação (PPGE-UNESP/PP). E-mail: anacrisambrosio@hotmail.com

\section{RESUMO}

O objetivo principal deste trabalho é mostrar a importância do diálogo entre professor e aluno no processo ensino-aprendizagem, principalmente em aulas de Matemática das classes de Recuperação Intensiva. Trata-se de uma pesquisa teórica concluída, que considerou algumas ideias de importantes educadores brasileiros, em especial Paulo Freire. O trabalho inicia-se com uma breve apresentação dos feitos do citado autor, seguindo pela justificativa de aprofundar os estudos de tal tema. Mostramos como Paulo Freire trata o diálogo em sua obra e como isto pode ser usado no ensino de Matemática. Finalizamos apontando a necessidade do diálogo nas salas de aula, forma em que o professor dá aos educandos reais oportunidades de construir o próprio conhecimento.

Palavras-chave: Ensino de Matemática, Paulo Freire, diálogo.

"O diálogo é o encontro entre os homens, mediatizados pelo mundo, para designá-lo. Se ao dizer suas palavras, ao chamar ao mundo, os homens o transformam, o diálogo impõe-se como o caminho pelo qual os homens encontram seu significado enquanto homens; o diálogo é, pois, uma necessidade existencial" (FREIRE, 1980, p.42).

\section{INTRODUÇÃO}

Paulo Freire é um dos mais importantes educadores brasileiros. Sua obra tem ultrapassado gerações, propondo transformações educacionais que favoreçam a libertação dos povos oprimidos. Tendo ingressado no ramo educacional em 1947, como diretor do departamento de Educação e Cultura do Sesi, onde teve os primeiros contatos com a alfabetização de jovens e adultos, Freire se debatia por uma educação comprometida com ética, que não se desvinculasse de seu caráter político, na qual a humanização dos seres humanos se concretizasse na dignidade da vida cotidiana das pessoas, na superação das realidades que as oprimem.

Para o autor, ensinar não podia ser apenas um processo de transmissão de conhecimentos, em que o aluno recebe os ensinamentos que o professor deposita, o que ele denominou "educação bancária", e a qual critica e descreve no livro "Pedagogia do Oprimido"(FREIRE, 1987). Ensinar seria um ato de amor, de coragem, de construção de conhecimentos, em que o debate e o respeito entre professor e aluno são imprescindíveis. 
Estudar as implicações das ideias deste autor nas mais diversas áreas da Educação é algo de extrema necessidade, por se tratar de pensamentos inovadores e atuais.

Neste artigo, apresentamos uma importante contribuição de Paulo Freire ao ensino de Matemática em salas de Recuperação Intensiva: a prática do diálogo. Na verdade é uma contribuição ao ensino de qualquer disciplina, porém com mais impacto sobre o ensino de Matemática, que até a atualidade é considerado por muitos professores como o ensino de verdades absolutas, no qual o professor transmite aos alunos um conhecimento pronto, acabado, e que deve ser aceito e aprendido sem intervenções.

Abordamos a questão das salas de Recuperação Intensiva pois desenvolvemos pesquisa de mestrado intitulada "A Recuperação Intensiva do Ensino Fundamental Ciclo II: uma análise da prática pedagógica do professor de matemática", na qual analisamos a prática de professores de matemática atuantes nestas classes, as quais são destinadas a atender alunos com maiores dificuldades de aprendizagem. Tais salas foram instituídas pela Secretaria Estadual de Educação do Estado de São Paulo no ano de 2012, constituindo-se em classes específicas para estes alunos, nas quais os professores deveriam trabalhar de forma diferenciada, para que no próximo ano os alunos retornem para as salas regulares.

No Estado de São Paulo os programas de recuperação da aprendizagem são essenciais para garantir uma boa qualidade educacional, visto que desde o ano de 1998 o Estado adota o regime de Progressão Continuada, o qual aboliu a organização do currículo em séries, instituindo os ciclos, não havendo mais a reprovação. Deste modo, em um sistema de classes tão heterogêneas, com alunos em diferentes níveis de conhecimento, e que, na maioria das vezes, impossibilita um trabalho individualizado com os alunos, a recuperação ou reforço escolar constitui mecanismo essencial para garantir que, ao final do ciclo, todos os alunos alcancem níveis melhores de aprendizado. Por tal motivo, analisar e avaliar a viabilidade de tais projetos é indispensável à garantia de um ensino de melhor qualidade, e mostrar melhores caminhos, um compromisso ético com a educação.

Portanto, o objetivo deste trabalho é mostrar como o diálogo entre professor e aluno é essencial no processo ensino-aprendizagem, pois somente através dele o professor tem condições de conhecer o pensamento do aluno e pode auxiliá-lo em suas dúvidas e inquietações sobre o que se está aprendendo. Principalmente nas salas de recuperação, nas quais os alunos tem maiores dificuldades de aprendizagem e para os quais o ensino tradicional não foi suficiente. 


\section{DIÁLOGO EM PAULO FREIRE}

O diálogo é inerente à condição humana. Comunicar-se é uma das necessidades primeiras dos seres, essencial à sobrevivência. Para Paulo Freire, o diálogo é o ponto central da atividade de ensinar, na qual professor e aluno são seres atuantes, igualmente importantes neste processo. É através da dialogicidade que ocorre a conscientização dos educandos, é a forma pela qual o professor demonstra respeito pelo saber que o educando traz à escola, e sem o qual não se pode ensinar.

Por esta razão Freire critica o que ele mesmo denomina de "educação bancária", prática muito comum no ensino de qualquer matéria. Nesta concepção, o professor é detentor do conhecimento, e "deposita" uma certa quantidade de conhecimentos nos alunos, que por sua vez, absorvem passivamente. $\mathrm{O}$ autor caracteriza tal prática através de dez propriedades, a saber:

(a) O educador é o que educa; os educandos, os que são educados; (b) o educador é o que sabe; os educandos, os que não sabem; (c) o educador é o que pensa; os educandos, os pensados; (d) o educador é o que diz a palavra; os educandos, os que a escutam docilmente; (e) o educador é o que disciplina; os educandos, os disciplinados; (f) o educador é o que opta e prescreve a sua opção; os educandos, os que seguem a prescrição; (g) o educador é o que atua; os educandos, os que têm a ilusão de que atuam, na atuação do educador; (h) o educador escolhe o conteúdo programático; os educandos, jamais são ouvidos nesta escolha, acomodam-se a ele; (i) o educador identifica a autoridade do saber com sua autoridade funcional, que se opõe antagonicamente à liberdade dos educandos; estes devem adaptar-se às determinações daquele; (j) o educador, finalmente, é o sujeito do processo; os educandos, meros objetos. (FREIRE, 1987, p. 34)

Desta maneira, esta concepção é um bom exemplo de educação antidialógica, na qual o educador transfere para o educando um conhecimento imposto, alienado, que não é passível de questionamentos. O educador detém todo o conhecimento, e o educando por sua vez, nada sabe. Sua curiosidade e criatividade são minimizadas ao máximo, e ao invés de transformar o mundo em que vivem, adaptam-se, ingenuamente. A esse respeito, Freire afirma:

Não é de estranhar, pois, que nessa visão "bancária" da educação, os homens sejam vistos como seres de adaptação, do ajustamento. Quanto mais se exercitem os educandos no arquivamento dos depósitos que thes são feitos, tanto menos desenvolverão em si a consciência crítica de que resultaria a sua inserção no mundo, como transformadores dele. Como sujeitos. (FREIRE, 1987, p. 34).

Portanto, quando se pratica a educação bancária, não há a difusão de conhecimentos verdadeiros, o que há é a memorização por parte dos alunos do que é depositado pelo professor, 
que por sua vez, efetuará um "saque" destes conteúdos na prova, momento em que os alunos deverão "devolver" ao professor o que foi "aprendido". Freire corrobora esta afirmação dizendo que, nesta perspectiva,

Não pode haver conhecimento pois os educando não são chamados a conhecer, mas a memorizar o conteúdo narrado pelo educador. Não realizam nenhum ato cognoscitivo, uma vez que o objeto que deveria ser posto como incidência do ato cognoscente é posso do educador e não mediatizador da reflexão crítica de ambos. (FREIRE, 1987, p. 40)

Em contrapartida, o autor propõe a educação problematizadora, na qual não se pode abrir mão da prática do diálogo. Tal prática rompe com os esquemas verticais característicos da educação bancária (FREIRE, 1987), superando, justamente através da dialogicidade, a contradição entre educador e educando. Assim,

(...) o educador já não é o que apensa educa, mas o que, enquanto educa, é educado, em diálogo com o educando que, ao ser educado, também educa. Ambos, assim, se tornam sujeitos do processo em que crescem junto e em que os "argumentos de autoridade" já, não valem. (FREIRE, 1987, p. 39)

Sendo assim, a concepção bancária nega a dialogicidade, servindo à dominação, enquanto que a concepção problematizadora, por sua vez, serve à libertação, afirmando-se no diálogo, sendo um ato cognoscente.

Freire propõe que a educação deva ocorrer através do diálogo, em que professor e aluno sejam igualmente sujeitos do aprendizado, de maneira que o conhecimento que o aluno já possui seja tão importante quanto àquele que o professor traz consigo, o que possibilita uma construção conjunta de saberes. Por esta razão, a humildade é característica primordial nesta prática, pois:

A auto-suficiência é incompatível com o diálogo. Os homens que não tem humildade ou a perdem, não podem aproximar-se do povo. Não podem ser seus companheiros de pronúncia do mundo. Se alguém não é capaz de sentir-se e saber-se tão homem quanto os outros, é que lhe falta ainda muito para caminhar, para chegar ao lugar de encontro com eles. Neste lugar de encontro, não há ignorantes absolutos, nem sábios absolutos: há homens que em comunhão, buscam saber mais (FREIRE, 1987, p.46).

Há também outras características essenciais ao educador que se comprometa com o real aprendizado de seus alunos através de uma educação problematizadora, libertadora, tais como paciência, amorosidade, fé nos homens. Tal professor precisa estar ciente de seu papel como educador, sabendo que não sabe mais do que seus alunos, apenas possui saberes diferentes. 
Precisa acreditar que o aluno também traz consigo saberes importantes, e sem os quais não conseguirá desenvolver novos conhecimentos. Daí a necessidade do diálogo, a necessidade de conhecer o aluno, saber o que ele sabe, para poder mostrar-Ihe novas possibilidades.

\section{O DIÁLOGO NO ENSINO DE MATEMÁTICA}

Embora a Matemática seja uma ciência fortemente presente no cotidiano das pessoas, tendo sido desenvolvida justamente em função das necessidades de sobrevivência do homem, a dificuldade e a recusa muitas vezes que grande parte das pessoas tem em relação à disciplina é preocupante. Por muitos anos, imperou no ensino de Matemática a ideia de que trata-se de uma disciplina em que o professor detém o conhecimento e deve transmiti-lo aos educandos, enquanto que os alunos, meros espectadores, devem ouvi-lo atentamente.

Aos poucos este modelo de ensino vem perdendo sentido na escola, principalmente em razão das legislações e pesquisas atuais, que norteiam para um ensino mais voltado a compreensão significativa dos alunos, para a qual o aluno deixa de ser apenas alguém que assiste a aula, para tornar-se alguém que participa da aula.

Surge neste contexto, o termo "análise de erros", segundo o qual, para saber o que ou como o aluno aprendeu é necessário que se verifique com profundidade suas respostas dadas em sala de aula, dando momentos para que ele se expresse, podendo assim auxiliar o professor no seu próprio processo de aprendizagem.

O erro então deixa de ser indesejável e meramente punível e passa a ser parte integrante do processo de aprender, revelando o pensamento do aluno, dando pistas ao professor do que aquele educando compreendeu, constituindo-se em um importante momento de aprendizagem para o professor, pois possibilita a ele compreender como os alunos se apropriam de um determinado conhecimento matemático (CURY, 2008).

De fato, não é somente considerar o erro, mas compreender o que há por trás da resposta que o aluno deu, pois acertar também não garante que ele aprendeu, como afirma Cury (2008):

“Na análise das respostas dos alunos, o importante não é o acerto ou o erro em si - que são pontuados em uma prova de avaliação da aprendizagem -, mas as formas de se apropriar de um determinado conhecimento, que emergem na produção escrita e que podem evidenciar dificuldades de aprendizagem." (Cury, 2008, p. 63) 
Desta forma, a partir da análise das respostas dos alunos o professor pode repensar sua maneira de ensinar, compreendendo melhor como o educando se apropria dos conceitos que está aprendendo, o que se torna um facilitador no processo ensino-aprendizagem.

Para tanto, o diálogo entre professor e aluno é fundamental, sem o qual o professor não poderá compreender como o aluno aprende determinado conteúdo, o que impossibilitaria sua real função como professor. A esse respeito, Lorenzato (2008) afirma:

"Ao professor compete, primeiramente, dispensar constante atenção para constatar o erro, lembrando que acerto pode camuflar erro. É importante diagnosticar como o erro se deu, sem o que será impossível encontrar a(s) causa(s) dele. Nessa fase, é fundamental ouvir o aluno, conversar com ele com o objetivo de desvelar seu pensamento e seus motivos. Feita a diagnose, convém propor ao aluno uma ou mais situações com as quais ele possa perceber a incoerência de suas respostas ou posições. Auxiliando o aluno a descobrir novas alternativas, podemos esperar que ele reformule seus conceitos, corrija o erro e, assim, evolua." (Lorenzato, 2008, p. 50)

Assim, tão importante quanto dominar os conteúdos, é, ao professor, saber ouvir o seu aluno, sem o que, mesmo com todos os outros recursos disponíveis, ele não poderá ajudá-lo a desenvolver um novo conhecimento. Logo, o diálogo é também essencial para que ocorra um bom ensino/aprendizado de Matemática.

\section{CONCLUSÃO}

Dada a importância que o diálogo assume no ensino de qualquer disciplina, seja para conhecer o pensamento de aluno, seja para a libertação de uma situação de dominação, em qualquer tipo de sala de aula, percebemos uma necessidade maior ainda de que ocorra a dialogicidade nas salas de Recuperação Intensiva.

Estas salas possuem no máximo 20 alunos, razão pela qual as possibilidades de conversas com os alunos são mais favorecidas, justamente por ter uma quantidade menor de pessoas. Os alunos que frequentam tais salas são aqueles com maiores dificuldades de aprendizagem, e que muitas vezes são estigmatizados como os "piores" alunos por outros colegas e professores.

Para que ocorra uma mudança nesta situação, e que estes alunos consigam aprender de fato, os professores destas salas precisam estar muito bem preparados para lidar com as mais diversas dificuldades, sabendo exatamente o que este aluno não sabe, porque ele não sabe, e como ele pode saber. Para isso, momentos de conversas nestas aulas são essenciais, conversas nas quais se fale com o outro, e não ao outro. 
Grande parte do envolvimento e interesse do aluno em seu próprio processo de aprender está nas mãos do professor, que decide qual o melhor caminho a seguir entre a dúvida e o conhecimento. Se considerar o pensamento do aluno, ouvi-lo e deixar que ele conjecture a sua maneira, ao invés de impor um modo de pensar já estabelecido, o professor dá aos aprendizes a oportunidade de construir o próprio conhecimento, que será muito mais significativo e duradouro. Daí a importância do respeito, da humildade e da confiança.

\section{REFERENCIAS}

CURY, Helena Noronha. Análise de erros: o que podemos aprender com as respostas dos alunos. Belo Horizonte: Autêntica, 2008.

FREIRE, Paulo. Pedagogia do Oprimido. 17ạ edição. Rio de Janeiro: Paz e Terra, 1987.

FREIRE, Paulo. Conscientização: teoria e prática da libertação - uma introdução ao pensamento de Paulo Freire. 3a edição. São Paulo: Cortez \& Moraes, 1979

LORENZATO, Sergio. Para aprender Matemática. 2a edicação. Campinas, SP: Autores Associados, 2008. 